\title{
Planning Criticism: Operative Contingencies in the Project of the Italian Tendenza
}

\section{Pasquale De Paola}

\begin{abstract}
In order to re-assess architecture's critical role and redefine the disciplinary domain of its production, this essay looks beyond forms of technocratic utopias, while it historically analyzes operative theoretical contingencies relative to the "project" of the Italian Tendenza, which is examined as an historical form of ideological criticism of the discipline of architecture and its contentious relationship between intellectual and capitalistic production. Particularly, this essay explores the ideological and historiographical production of the 1960s and 1970s. This was when the term Rationalism and its theoretical body of work acquired renewed prestige replacing the ephemeral aesthetic of the Modern Movement with a grounded and critical discourse based on Aldo Rossi's and Massimo Scolari's position relative to the need for architecture to re-affirm its own statute, in order to free itself from any form of technocratic utopia. While questions of interdisciplinarity remain essential toward an understanding of future architectural contingencies, it is only by questioning the status quo of architecture and re-examining its past that a new sense of criticality can be generated.
\end{abstract}

Keywords: Critical Call, Aldo Rossi, Massimo Scolari, Manfredo Tafuri, Tendenza

"The critical act will consist of a recomposition of the fragments once they are historicized: in their remontage." (Manfredo Tafuri) ${ }^{1}$ 


\section{THE WILL TO THE CRITICAL}

Contemporary architectural production seems to be generally defined by the recent fascination with speculative technologies and interdisciplinary processes. However, it has also become evident that its sense of criticality appears to lack the discursive specificity or a tendency that sees architecture as a form of internal knowledge characterized by its inherent will to the critical. It also re-assesses the importance and centrality of the architectural artifact as the point of reference for a reestablished sense of criticality. Accordingly, the opening position of this essay is that rather than addressing what Georg Simmel called "overstimulating processes of technical rationalization," 2 it is time to shift our attention to the architectural work and critically historicize its conceptual framework by defining its internal domain.

"The most theoretically aware of contemporary architects have rejected what was the most important operative concept of architecture theory at the moment of its re-foundation in the 1970s: namely, the aspiration toward autonomous forms and techniques to create and measure the distance between a resistant, critical practice and the degraded languages and ideologies of consumer culture that surround it."

(K. Michael Hays) ${ }^{3}$

Threatened by technological optimization, the concept of autonomy appears to reaffirm architecture's own disciplinary resistance whose ultimate goal is to recapture its critical role within the contemporary. ${ }^{4}$ This essay strives to outline a more historical model of critical investigation that sees architecture as a comprehensive design practice characterized by internal ideological and theoretical resistance. Most importantly, this understanding implies the existence of a condition, which is emphatically defined by the Kantian conviction that the critical represents "knowledge within knowledge," a position that, in Robert Somol's words, "turns up attention causing an awareness, a selfreflective search for meaning, as in a formalism or writings." ${ }^{5}$ Indeed, the critical matters primarily because it offers an opportunity to resist within a disciplinary field that appears to be expanding and stretching to the point of non-return. While questions of interdisciplinarity remain essential toward an understanding of future architectural contingencies, it is only by questioning the status quo of architecture and re-examining its past that a new sense of criticality can be generated.

In order to re-assess architecture's critical role and redefine the disciplinary domain of its production, this essay looks beyond forms of technocratic utopias, while it historically analyzes operative theoretical contingencies relative to the project of the Italian Tendenza. This movement is examined as an historical form of ideological criticism of 
the discipline of architecture and its contentious relationship between intellectual and capitalistic production. Particularly, this essay explores the ideological and historiographical production of the 1960s and 1970s. This was when the term Rationalism and its theoretical body of work acquired renewed prestige replacing the ephemeral aesthetic of the Modern Movement with a grounded and critical discourse based on Aldo Rossi's and Massimo Scolari's declaration that "Architecture needed to return to the affirmation of its own statute" ${ }^{6}$ in order to free itself from any form of technocratic utopia. Yet, before familiarizing with the ideological project of Tendenza, I believe that it is opportune to address Manfredo Tafuri's operative provocations, whom in a labyrinthine way "planned" Tendenza's critical project as a tendentious response to the sterile production of Modernism and its apathetic fascination with capitalistic modes of architectural production.

\section{PLANNING CRITICISM}

"The scandal of Stirling's architecture is constituted by man, as he is forced to ricochet between architecture as pure object and the redundancy of hermeneutic messages, deranged by a rhetoric of interruption. The architecture of Aldo Rossi eliminates such a scandal. Its reliance upon form excludes all justifications from outside. The distinctive features of architecture are inserted into a world of rigorously selected signs, within which the law of exclusion dominates." (Manfredo Tafuri) ${ }^{7}$

Prolific and equally provocative for his cynical views on architecture, Manfredo Tafuri has to be considered the most prominent and equally nihilistic mastermind of a critical attitude that saw history as a project dictated by ideological specificity and disciplinary autonomy. This is particularly evident in his introduction to The Sphere and the Labyrinth (1980), in which Tafuri analyzes the peculiarities of "the historical project "intended, as Marco Biraghi pointed out, ${ }^{8}$ as a critical examination and understanding of history as a "subjectively designed" arrangement of events and facts underlined by breaking points that meant to disrupt the ordinariness of architecture. While extremely dense and convoluted to the point of compromising the readability of the text itself, Tafuri examines the contingent relationship between the architect and the historian as well as their shared operative field of action. Yet, while the architect pragmatically objectified the past and present via the designed, the historian had to stimulate and provoke a reaction contingent to its contextual framework. Tafuri accomplished that by constructing a highly rhetorical narrative characterized by critical points of rupture, which allowed him to discuss history's cyclical sense of crisis. Within this scheme, it is the critical that generates the crisis, and consequently, it is the historian's responsibility to provide a solution, a tendentious one, which is critically and contextually derived from the crisis itself. How 
do we establish this operative sense of criticality? In order to answer this question, it is important to reiterate Tafuri's concept of "Operative Criticism":

'What is normally meant by 'operative criticism' is an analysis of architecture (or the arts in general) that, instead of an abstract survey, has as its objective the planning of a precise poetical tendency, anticipated in its structures and derived from historical analyses programmatically distorted and finalized." 9

"Operative Criticism," which originates from Critical Theory, is defined as the meeting point between history and design. It is criticism that comes from the architect or the historian in an attempt to manifest a vision or make a change. Rather than developing a linear historical survey, operative criticism distorts history creating multiple layers of narratives with the intention of projecting tendencies forward out the past. The final result of criticism is the artifact generated out of the study of existing architecture.

Therefore, criticism moves from the media of description to the medium of architecture itself where history becomes infected with a sort of critical subjectivity that ends up influencing future architectural production. It is not a mere recollection of events all chronological spaced, but it becomes a new critical artifact that redefines the positioning of a certain tendency and its level of artistic and moral productivity. ${ }^{10}$ In order to expose this operative sense of criticality, in Theories and Histories of Architecture (1968), Tafuri discusses the historiographical meaning of the work of Giovanni Pietro Bellori and his critical rejection of Baroque as a prime example of operative criticality applied to change future artistic contingencies. However, the most important component of such a methodology finds its own justification within the critical nature of the outcomes presented, which create, in Tafuri's words, a "ready-made judgment" of value for analytical rigor. ${ }^{11}$

It is a new kind of criticism that essentially departs from the objective endorsing the subjective. Why is this tendentious model still relevant? The answer has to be found in its constructed narrative that, via a critical manifestation of the historiography of the present, proposes an architecture characterized by "unprejudiced experimentalism." It is a new sense of criticality that plans its own future expressions by being critical of both the past and present. This is particularly evident in Manfredo Tafuri's History of Italian Architecture, 1944-1985:

"After the end of the Second World War, architects who were obliged to respond to the new Italian reality were faced with a difficult dialectic between knowledge and action - difficult, because of the contradictory foundations underlying the tradition of the discipline, but also because of the many levels imposed on such knowledge. This was all the more true given that most 
competent members of the profession took it for granted that there could be no knowledge divorced from action: an encounter with active politics seemed imperative." 12

Tafuri's description is unescapably gloomy: Italian architecture had ended up falling victim of a technocratic process characterized by academic and professional arrivism, which had consequently turned architecture into a deeply rhetorical discipline. However, it is in the work of Aldo Rossi, Giorgio Grassi and Massimo Scolari, that Tafuri calculatedly finds the answers to this crisis; a silent and isolationistic position that critically forces architecture to look internally in order to survive. ${ }^{13}$ More specifically, Tafuri recognizes the intrinsic criticality of Rossi's and Grassi's methodology based on the merging of architectural criticism with the criticism of the city through a catalog of autonomous principles, which, according to Tafuri, are clearly and formally expressed in the work of the two Milanese architects.

Thus, to re-examine architecture criticality and its disciplinary domain, the rest of this essay investigates the development, evolution, and persistent presence of a theoretical and critical attitude identifiable in the work produced by Tendenza, an heterogeneous group of Italian architects close to Aldo Rossi and Massimo Scolari, and which proposed an autonomous process of urban and typological internalization as juxtaposition to the modernist homologation of a universal language "sent from above." 14

\section{CONTRA MODERNISM: THE PROJECT OF TENDENZA}

Tendenza, originally formulated as a methodological response to the reductive aesthetics of Modernism and the International Style, is usually associated to a Milanese and Venetian group particularly close to Aldo Rossi, Massimo Scolari and Carlo Aymonino, and which also included other members who had a strong influence in other Italian circles such as Antonio Monestiroli, Salvatore Bisogni, Uberto Siola, Gianni Braghieri, Franco Raggi, Ezio Bonfanti, and Daniele Vitale. While looking at its linguistic roots, the word tendenza means "an attitudinal predisposition to act and behave in a certain ideological way;" ${ }^{15}$ the term itself implies a well-defined programmatic orientation driven by a common idea or methodological practice. This definition certainly provides the basic underlying principles of this critical discourse, which was characterized by an autonomous and disciplinary impulse shared by many individuals.

Also labeled as Neo-Rationalism, the Italian Tendenza was never a homogeneous movement that produced a relatively similar architectural style (as the term Neo-Rationalism might erroneously imply); on the contrary, Tendenza listed a very heterogeneous number of practitioners and academics that shared a similar interest toward an understanding 
of architecture and its urban methodological investigation. Indeed, Tendenza, was understood as praxis indicative of a certain disciplinary disposition elucidated by an autonomous methodology based on a typological classification and the practical application of an established building logic. While formally diverse, this tendency was ideologically characterized by a return to the traditional rationality of Modernist architects, such as Ludwig Hilberseimer, Adolf Behne, Hans Schmidt, and Adolf Loos. Tendenza's production exemplified a method of disciplinary inquiry that prioritized the importance of the idea over the image and the integration of both criticism and design. Architecture was to be, in Scolari's words, a fenomeno autonomo, a process that required disciplinary refounding while rejecting interdisciplinary remedies as well as political, economic, social and technological contaminations. ${ }^{16}$

Particularly, the project of Tendenza and its typological and rational framework appears to offer an interesting case study, which emphasized a design practice based on a critical and typo-morphological methodology that sought resistance through autonomy (Fig. 1). Therefore, in order to investigate the critical mechanisms relative to this self-reflective attitude, the conclusive part of this essay analyzes the theoretical work of Aldo Rossi and Massimo Scolari, two of the most proactive leaders of a tendency, which pursued the critical through the assimilation of "architecture as an instrument of culture" and "architecture as autonomous form." 17

\section{TOWARD A TYPOLOGICAL CRITICISM}

"The thread of Ariadne with which Rossi weaves his typological research does not lead to the 're-establishment of the discipline,' but rather to its dissolution, thereby confirming in extremis the tragic recognition of Georg Simmel and Gyorgy Lukacs: 'a form that preserves and is open to life, does not occur.'” (Manfredo Tafuri) ${ }^{18}$

With the publication of The Architecture of the City in 1966, Aldo Rossi launched a redefinition of the discipline grounded into an autonomous understanding of architecture and the formation of the modern European city. Rossi asserted the project of working on a technical survey of the city as an artifact, setting up architecture itself as the measure of architecture and explicating its genesis through its own principles. In its fragmented nature, the city is both an architectural artifact and a collection of fatti urbani, ("urban artifacts," as in the English translation of the book, or faits urbain as indicated by Marcel Poëte in his An Introduction to Urbanism: The Historical City ${ }^{19}$ ), which present their own particular formal expression. Similarly to Manfredo Tafuri's historical project, Rossi places more emphasis on particular points of rupture which he calls fatti urbani, and that accordingly embody generative components that validate typological 


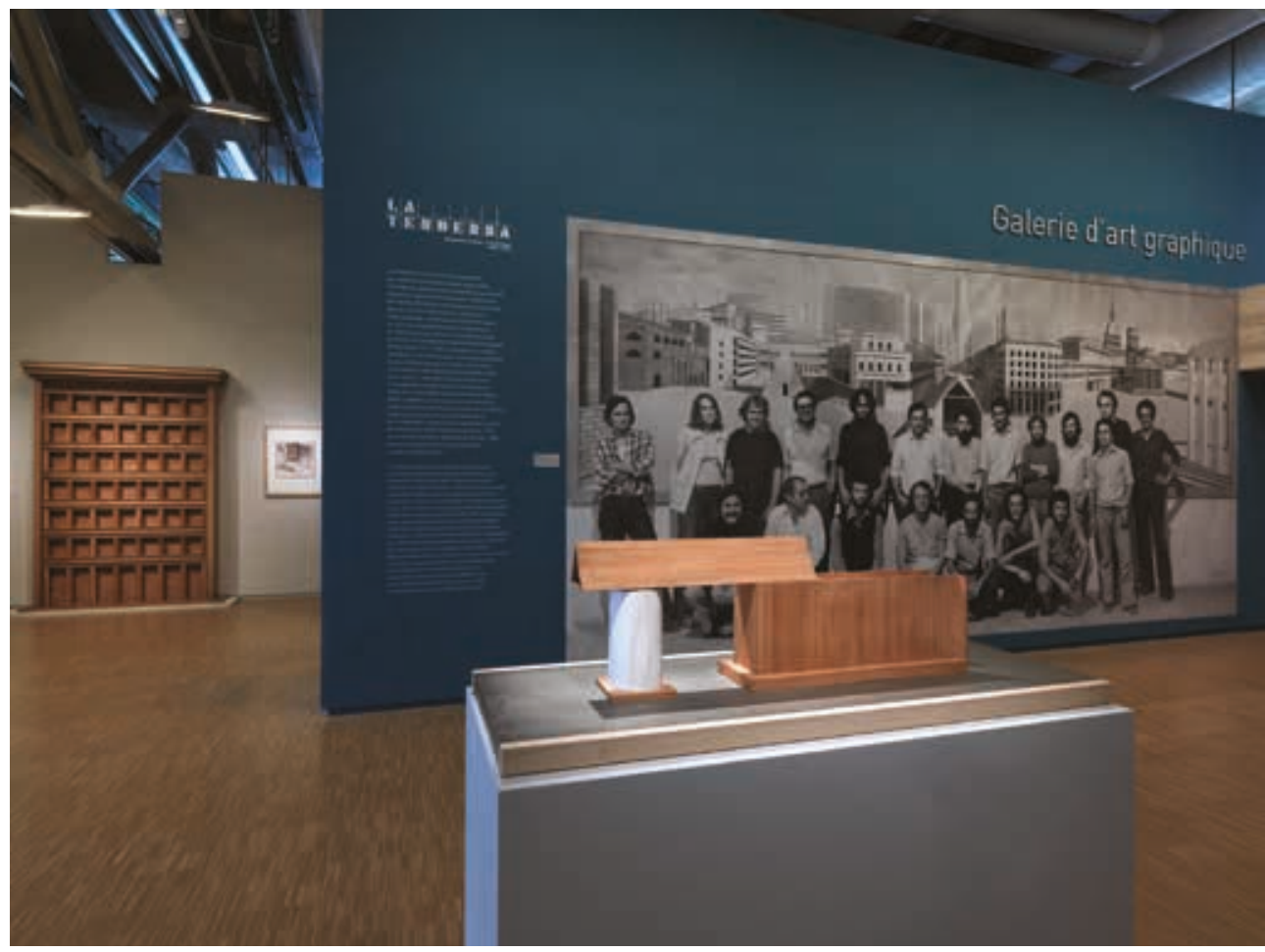

Figure 1. La Tendenza: Italian Architectures 1965-1985, Centre Pompidou, Paris (June 20 - September 10, 2012). @ Philippe Migeat/Centre Pompidou.

and morphological variations. The city, as an accumulation of fatti urbani, can be formally and typologically analyzed via redrawing its parts in order to dissect anomalies within its plan. However, Rossi's typological classification is not aimed at generalizing the process of urban growth and redesigning of the city; instead it recognizes the presence of particular typological signifiers that link past and present, life and society, and which revolve around monuments. ${ }^{20}$

The structure of those fatti urbani has to be precisely identified in order to avoid a generic assessment based on simplistic conclusions. Rossi's observation is essentially defined by the study of form as it relates to those urban events comprehensively analyzed in their social, political, and civic connotations, and which are capable of generating form. The functional individuality of the architectural object is not as important as its morphological and formal connotation, which appears to become more demarcated at the city scale exposing emergent forms and specific building types that seem to share significant artistic and civic connotations (Fig. 2). Typology, as the study of types that can't be reduced anymore, becomes the critical factor that exposes the singularity of architecture. Within this framework, the architect is subjectively responsible for a critical representation of the city that proposes planning decisions based on a more morphologically contextual formal reorganization. 
While identifying specific permanent points, Rossi uses history and its critical narrative as a way to underline how particular events have redefined the development and formal layout of the city. The presence of particular monumental singularities is often related to significant events in time. The events can be political, social, religious, and they can also be associated to specific rituals of iconography. Those significant events are usually distinguishable by monuments, which tend to guide the principles of urban growth. Yet, in order to be able to understand the relationship between primary urban attractors and human collectiveness, we have to recognize the role of history in its social connotations. According to Rossi, the history of architecture is not only the history of stylistic progression, but it is also the validation of chronicles of civic and social interactions, consolidated overtime by a collective mnemonic will. Reacting against what he calls "naïve functionalism," ${ }^{21}$ Rossi sets the historical production of architecture as the measure of architecture, a system that understands the presence of archetypes, which, in their singularity, contain the information necessary to generate form. Those archetypes have a precise internal structure, which is both civic and collective; thus, in order to rationalize this building logic, we have to understand the city as a comprehensive repository of architectures (or types) systematically fragmented in order to identify and provide a critical recognition, definition, and analysis of particular generative events.

Widely published and analyzed, The Architecture of the City has been hardly evaluated as a comprehensive compendium of typological criticism, written with the primary intention to celebrate the historiography of early Rationalism, while uncovering typological laws of architecture production that critically define both the structure of the city as well as its monumental artifacts. ${ }^{22}$ Indeed, the necessity to apply a logical process to a field so complex was a peculiarity necessary to the formation of a methodological discourse, a tendency, critical of its past but also surprisingly optimistic about its future. For Rossi, a good architect is the one who continuously tests and validates his/her theoretical work by producing buildings according to specific operative and critical principles, merging architectural criticism with the criticism of the city. This obsessive practice is essentially at the basis of what Rossi calls Razionalismo Esaltato, ${ }^{23}$ a type of rationality that is extremely fanatic in its obsessive search for an autonomous and rational logic, critical and aware of realistic problematics.

\section{ARCHITECTURE AS COGNITIVE RESEARCH}

"For Tendenza, architecture is a cognitive process that in and of itself, in the acknowledgement of its own autonomy, is today necessitating a refounding of the discipline; that refuses interdisciplinary solutions to its own crisis; that does not pursue and immerse itself in political, economic, social, and technological 
events only to mask its own creative and formal sterility, but rather desires to understand them so as to be able to intervene in them with lucidity not to determine them, but not to be subordinate to them either." (K. Michael Hays) ${ }^{24}$

Predominantly recognized for his work and research on the methods of architectural representation, ${ }^{25}$ Massimo Scolari's theoretical work offers a peculiar understanding of autonomy as a "cognitive process" characterized by precise disciplinary and epistemic principles. More precisely, Scolari, attempting to set up a theory of architectural knowledge, looks at the role of history as a container of situations and failures that necessitates to be rationally and internally examined in order to provide realistic responses. Indeed, it is a reasoning process that refuses interdisciplinary solutions to its own crisis. ${ }^{26}$ Most importantly, Scolari supports the distancing from utopian radicalism, which he sees formally and ideologically expressed in the work of Superstudio, Archizoom, UFO, and Gruppo 9999, and that had to be primarily blamed (largely thanks to Tafuri's operative interpretation) for its negative connotation of historical analysis. This characteristic certainly

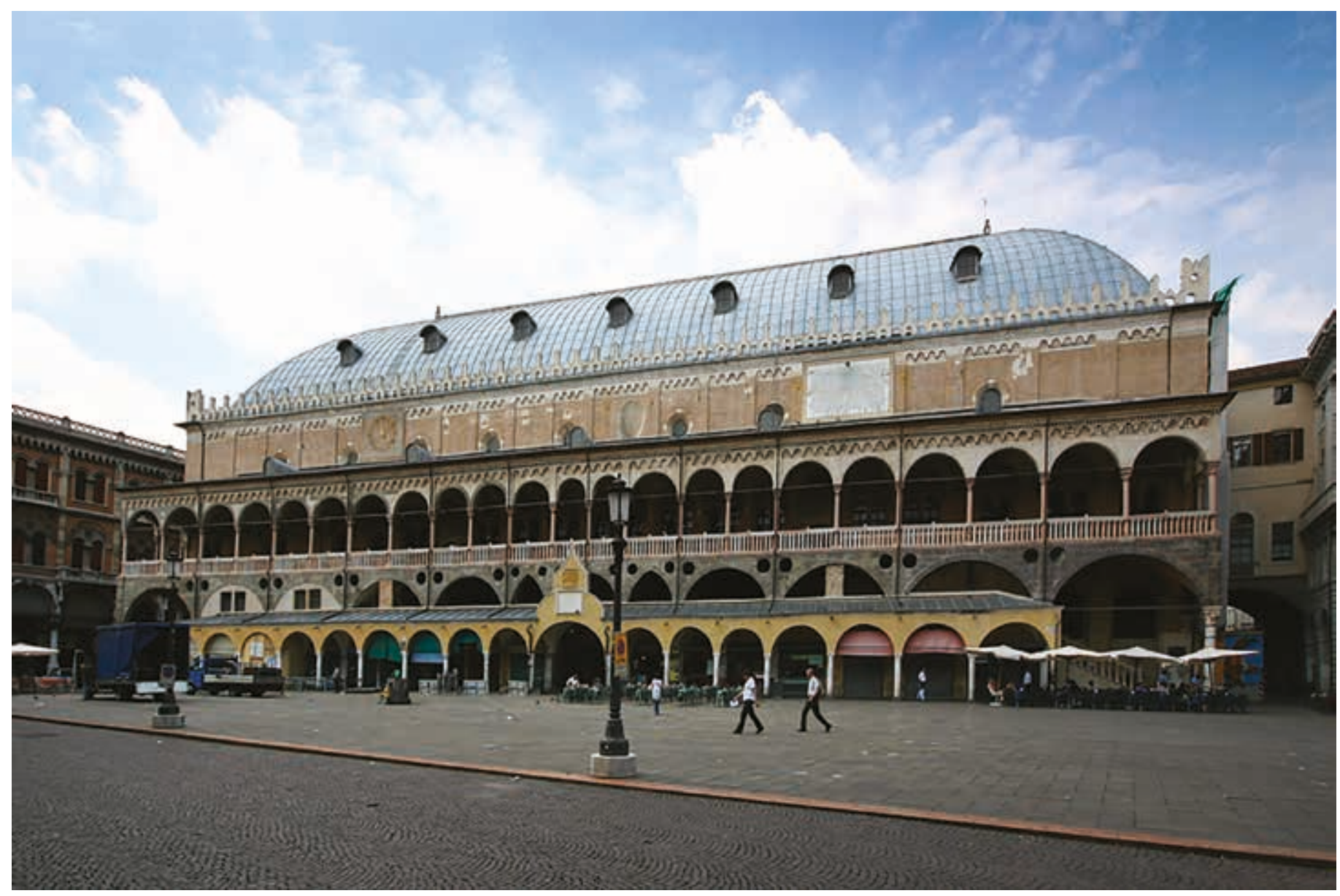

Figure 2. Palazzo della Ragione and Piazza delle Erbe, Padua (Italy). (c Stefan Bauer. 
isolated the radicals' work from the reality of things, proposing utopias as a non-feasible solution. ${ }^{27}$ Scolari explains that groups like Superstudio or Archizoom pursued purely cultural prefigurations rather than a grounded approach based on disciplinary modalities, thus reducing architectural production to a pseudo-metaphor.

Architecture, in the end, had to reflect on its own internally generated laws or norms and it had to express and display itself through a reactive architectural representation based on a morphological and typological analysis.

Scolari recognizes this critical attitude in what he calls Tendenza, a rather heterogeneous group of architects interested in cognitive methods that offered a rather critical analysis of the city intended as a collection of urban types and monumental references. Scolari states that architecture has to be perceived as a mental process, underlined by the existence of an autonomous framework characterized by its own rules, history, and forms. ${ }^{28}$

Accordingly, the importance of the masters of early Modernism is critically framed by looking at the methodological work of Ernesto Nathan Rogers, Giuseppe Samoná and Ludovico Quaroni. Specifically, they stressed the importance of urban analysis as an epistemic process of architectural discovery as well as the significance of historical continuity as a way to critically project forward the tradition of early Modernism. Most importantly, Scolari identifies the significance of cognitive research via disciplinary autonomy as the only possible way to isolate generic forms of academism and architectural professionalism, which historically seemed to deny architecture's own internal and intellectual distinctiveness. To eradicate those two problems, Scolari proposes a comprehensive and methodical refounding of the discipline based on a critical approach that refuses any contamination or political and technocratic intrusion. ${ }^{29}$

The beginning of this tendency is particularly identifiable in the early work of Ernesto Rogers at Casabella, and Giuseppe Samoná at the IUAV (Istituto Universitario di Architettura di Venezia - the Venice school of architecture), who had advocated a return to architecture's own analytical and cognitive processes, a position also previously emphasized by both Franco Albini and Piero Bottoni. Within this framework (and according to Scolari), Aldo Rossi, Guido Canella, and Giorgio Grassi appear to be the only architects capable of developing a critical understanding of the relationship between analysis and design, residential typology and urban morphology.

Similarly to Rossi's The Architecture of the City, Scolari proposes an architectural response that emphasizes the logic of types and typological thinking as an epistemic possibility for the new. Interestingly enough, for Scolari, the only way to avoid "secular functionalism" and "extreme organicism" is the return to the basic rules of architecture, which he 


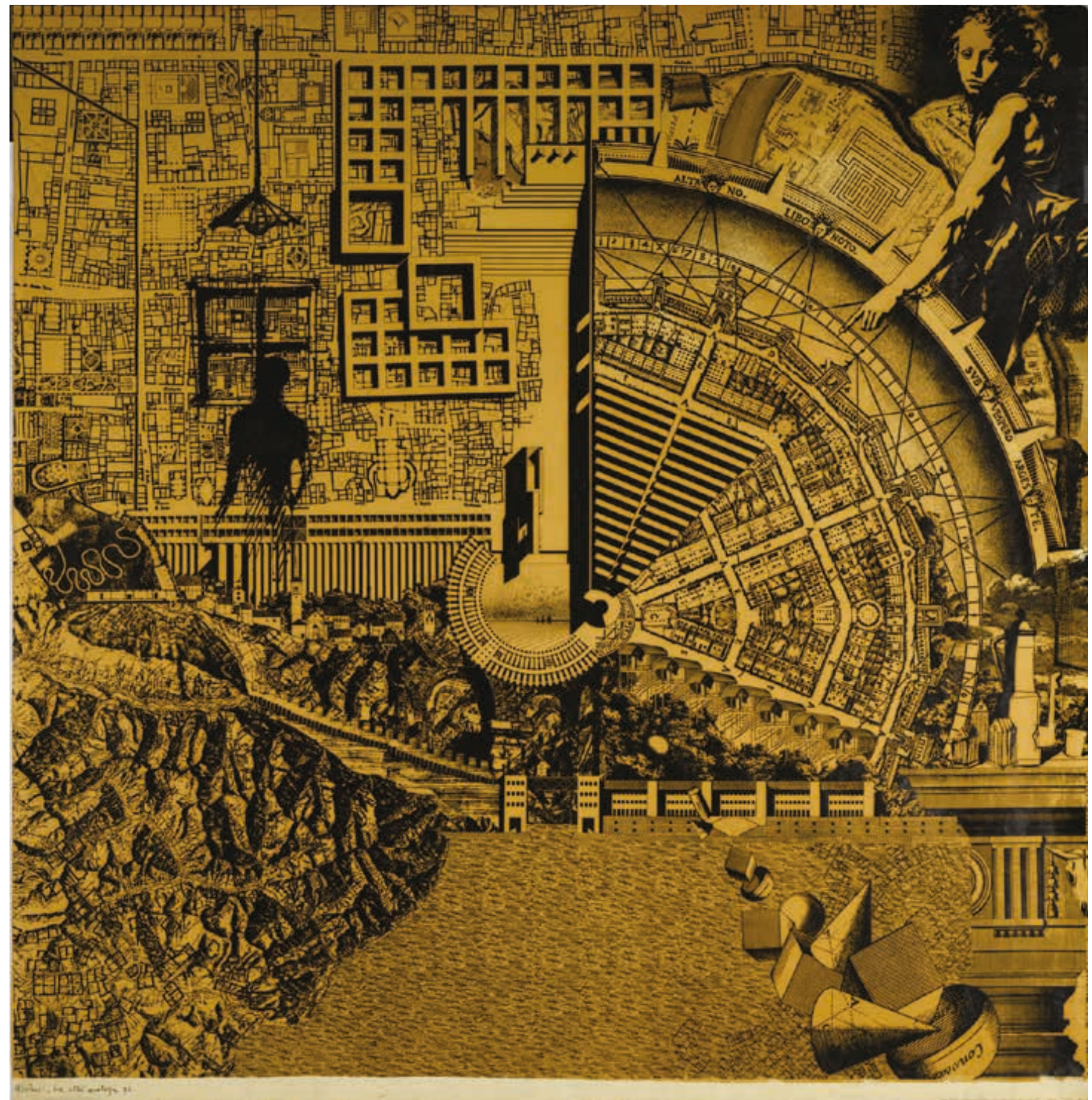

Figure 3. Aldo Rossi, with Fabio Reinhart, Bruno Reichlin and Eraldo Consolascio, La città analoga, collage, various materials, $200 \mathrm{~cm}$ x $200 \mathrm{~cm}$ (6' 6" x 6' 6"), 1976. Collezione privata. (c) Eredi Aldo Rossi, courtesy Fondazione Aldo Rossi. 
explicitly recognizes into the early work of Aldo Rossi. ${ }^{30}$ In fact, Rossi identifies the presence of types and models that reappear through history and that also modify the structure of the city. This progression was clearly addressed in the collage La città analoga (1976), where Rossi exposed the primary archetypical essence of monuments and their role on the formation and consolidation of what he called fatti urbani (Fig. 3). ${ }^{31}$ Scolari uses this very same framework as a way to set up the formal basis of a new architectural discourse based on cognitive continuity, which is accomplished through the recognition of particular building types that link past and present, while avoiding any formal and stylistic contamination.

Architecture's relation to history is also explained by its urban and contextual specificity defined by how particular artifacts underline the presence of a methodological monumentality. This is based on the inner necessity for an artifact to emerge as a symbol of relevant urban phenomena. Accordingly, history, type, and monuments are recognized as the most important cognitive elements that define the critical nature of the design process. Thus, in order to develop a new design sensibility, Scolari proposes a relatively new theory of architectural production, which is not only mediated by historicity and authenticity, but it is also framed by a critical method of rational analysis that emphasizes both the analytical and morphological importance of its parts and fragments. ${ }^{32}$

\section{CONCLUSIONS}

The distinctive sense of criticality evident in the work of Rossi and Scolari seems to validate the initial postulates that sought architecture as a form of internal knowledge characterized by a will to be critical, while re-assessing the importance and centrality of the architectural work as the focal object of theoretical discourse. Tendenza and particularly the work and guidelines set by both Rossi and Scolari underlined the establishment of an architectural practice based on the operative recurrence of the historicity of the discipline and its autonomous framework in order to redefine the methodological bases of architecture. This was accomplished by proposing a consistent rational attitude based on the relationship between analysis and design, architecture and ideology, rationality and invention. ${ }^{33}$ Hence, a tendency was established when description, manipulation, expression, and representation of knowledge were cohesively integrated in order to generate a discourse based on those critical principles of rationality and logic that seem to underline the architectural process and its formative and generative production.

Methodologically speaking, Tendenza's framework proposed a critical examination of the city as an artifact in transition characterized by particular typological variations, which had to be expressed by redrawing its internal and distributive parts. Interestingly enough, this process 
was identified by a critical agenda that pursued the internalization of architecture as an autonomous discourse characterized by the inescapable accumulation of forms, solutions and building types. Accordingly, Tendenza's approach freed the urban artifact of any historical or formal ambiguity keeping it timeless and authentic. Indeed, it is only by questioning the historicity of architecture that a new sense of criticality can be generated. Fundamentally critical in its ideological nature, the project of Tendenza assumed specific significance in generating and consolidating a new autonomous metanarrative that aimed to challenge and replace the fading objectivist agenda of Modernism. While Rossi will eventually replace this autonomous framework with a more melancholic and object-derived method of analysis based on the axiom "I don't invent, I remember," ${ }^{44}$ Tendenza's legacy has to be found in the evident expression of its will to the critical. Without this internal condition, architecture cannot progress.

\section{Notes}

1. Manfredo Tafuri, The Sphere and the Labyrinth: Avant-Gardes and Architecture from Piranesi to the 1970s, trans. Pellegrino d'Acierno and Robert Connolly (Cambridge MA, USA: The MIT Press, 1995), 15; Italian or. ed. La sfera e il labirinto: Avanguardie e architettura da Piranesi agli anni '70 (Turin, It.: Einaudi 1980).

2. Georg Simmel, "The Metropolis and the Mental Life," in The Sociology of Georg Simmel, ed. Kurt Wolff, trans. H. H. Gerth with C. Wright Mills (New York: Macmillan, 1950), 413; German or. ed. Die Großstädte und das Geistesleben, 1903.

3. K. Michael Hays, "Prolegomenon for a Study Linking the Advanced Architecture of the Present to That of the 1970s through Ideologies of Media, the Experience of Cities in Transition, and the Ongoing Effects of Reification," Perspecta, vol. 32, (2001): 101.

4. See ibid, 102.

5. Robert Somol, as quoted by Peter Eisenman in "Autonomy and the Will to the Critical," Assemblage, no. 41 (April 2000): 90.

6. K. Michael Hays, Architecture Theory since 1968 (Cambridge MA, USA: The MIT Press, 2000), 124.

7. Tafuri, The Sphere and the Labyrinth, 273.

8. Marco Biraghi, Project of Crisis: Manfredo Tafuri and Contemporary Architecture, (Cambridge: The MIT Press, 2013), 13.

9. Manfredo Tafuri, Theories and History of Architecture. (New York: Harper \& Row, 1980), 141; English first ed., trans. G. Verrecchia (London: Granada, 1976; Italian or. ed. Teorie e storia dell'architettura (Bari, It.: Laterza, 1968).

10. See Panayotis Tournikiotis, The Historiography of Modern Architecture (Cambridge MA, USA: The MIT Press, 1999), 214.

11. Tafuri, Theories and History, 145.

12. Manfredo Tafuri, History of Italian Architecture: 1944-1985, trans. Jessica Levine (Cambridge MA, USA: The MIT Press, 1990), 3; or. Italian ed. Storia dell'architettura italiana 1944-1985 (Turin, It.: Einaudi, 1986).

13. See ibid, 136.

14. Bruno Zevi, The Modern Language of Architecture (Seattle: University of Washington Press, 1978), 6; Italian or. ed. II linguaggio moderno dell'architettura (Turin, It.: Einaudi, 1973).

15. Dictionary of Italian language, Garzanti ed.: "Tendenza."

16. See Hays, Architecture Theory Since 1968, 124. This excerpt was also published in Aldo Rossi, Ezio Bonfanti, Architettura Razionale, (Milan: Franco Angeli, 1973), 153-188. "Fenomeno autonomo" literally means "autonomous phenomenon."

17. Hays, "Prolegomenon ....": 103. 
18. Manfredo Tafuri, L'Architecture dans le Boudoir: the Language of Criticism and the Criticism of Language," Opposition, 3 (1974): 56. Also in K. Michael Hays, Architecture Theory Since 1968, 155.

19. Marcel Poëte, Introduction à l'urbanisme. L'evolution des villes, la leçon de l'antiquité (Paris: Boivin \& Cie, 1929).

20. See Aldo Rossi, L'architettura della città, (Milan: Città Studi, 1978), 35-36; or. ed. (Padua, It.: Marsilio, 1966); English ed., trans. Diane Ghirardo and Joan Ockman (Cambridge MA, USA: The MIT Press, 1982).

21. See ibid., 46.

22. See Tafuri, Theories and History, 158.

23. Aldo Rossi, Scritti scelti sull'architettura e la città, 1956-1972, ed. Rosaldo Bonicalzi (Milan: Città Studi, 1997), 347; or. ed. (Milan: Clup, 1975).

24. Hays, Architecture Theory Since 1968, 124. This excerpt was also published in Aldo Rossi, Ezio Bonfanti, Architettura Razionale, (Milan: Franco Angeli, 1973), 153-188.

25. See the retrospective Massimo Scolari: The Representation of Architecture, 1967-2012 held at the Yale School of Architecture in 2012.

26. See Massimo Scolari, "Avanguardia e nuova architettura," in Aldo Rossi and Ezio Bonfanti, Architettura Razionale, (Milan: Franco Angeli, 1973), 156.

27. See ibid., 158.

28. See ibid., 131

29. See Carlo Manzo, "Per un' architettura di tendenza," in Controspazio, no. 6 (December, 1973): 95

30. See Scolari, "Avanguardia e nuova architettura," 170.

31. Aldo Rossi, L'architettura della città, (Milan: Città Studi, 1978), 21.

32. See Scolari, 184-85.

33. See Aldo Rossi, "L'obiettivo della nostra ricerca," in L'analisi urbana e la progettazione architettonica (Milan: CLUP, 1970), 13-20.

34. Aldo Rossi, as quoted in Germano Celant and Diane Ghirardo, Aldo Rossi Drawings,

ed. Luca Molinari (Milan: Skira, 2009), 11.

\section{Acknowledgement}

This essay originated as a paper presented on a session called "Critical Call," at the $104^{\text {th }}$ Annual Meeting of the Association of Collegiate Schools of Architecture in Seattle, WA, on March 19, 2016. This is a revised version of the paper published in the $104^{\text {th }}$ ACSA Annual Meeting Proceedings, Shaping New Knowledges (Washington D.C.: ACSA Press, 2016).

Pasquale De Paola, Ph.D., LEED AP, is the Howard Endowed Professor and Program Chair in the Architecture Program at Louisiana Technological University (Louisiana, USA). Pasquale has also taught at Columbia GSAPP and Texas A\&M. Pasquale holds a B.Arch. from LSU and a M.S. in Architecture and Urban Design from Columbia. He also received his Ph.D. from Texas A\&M; his dissertation "A Question of Method" examined the methodological framework established by the Italian Tendenza and the Milan Triennale exhibition of 1973. His dissertation was awarded the ARCC King Medal for architectural research in 2011.

Professionally, Pasquale has practiced for Carlo Aymonino in Rome and the Richard Rogers Partnership. His research interests include Italian architectural culture, architectural criticism, history and theory of contemporary architecture, and design methods.

E-mail: pdepaola@latech.edu 